\title{
THE IMPACT OF KONKAN RAILWAY PROJECT ON THE AVIFAUNA OF CARAMBOLIM LAKE IN GOA
}

\author{
A.B. Shanbhag, R. Walia and S.D. Borges \\ Department of Zoology, Goa University, Goa 403206, India \\ Email: shanbag@unigoa.ernet.in
}

\begin{abstract}
The Carambolim Lake $\left(73^{0} 55^{\prime} \mathrm{N} \& 15^{\circ} 30^{\prime} \mathrm{E}\right)$ in Goa, is an age old minor irrigation tank known for its rich bird fauna. Conflicting opinions were aired as to the ecological damage likely to be caused to the lake environs owing to the Konkan Railway track alignment in its immediate vicinity. A long term qualitative and quantitative analysis of the bird fauna of the lake was undertaken from January 1996 to July 1998. The lake harboured 92 species of birds including 17 winter visitors. Many of the new sightings during the year 1997 were truly terrestrial birds like shrikes, parakeets, etc., while some like Rosy Starlingand Brown-headed Gulls were mere vagrants to the area. Therefore, the sightings of 23 additional species of birds during the year 1997 need not be considered as a sign of qualitative improvement of the avifauna over that of the previous year. However, there was a perceptible increase crossing in the cumulative total of birds in general and that of waterbirds in particular, during 1997. Likewise, the percent increases in the cumulative strength of the dominant winter visitors such as Pintails and Lesser Whistling Ducks during 1997 were 81 and 340 respectively. These can be construed as sure signs of recovery by the avifauna of the lake, during a relatively tranquil operational phase (1997) from the peak disturbances caused by the construction activity (1996). All the same, the lake needs protection from other threats like encroachment and incessant silting.
\end{abstract}

\section{Key words}

Avifauna, Carambolim Lake, impact, Konkan Railway project, Goa, checklist

\section{Introduction}

In Goa, since colonial days, rabi crop of paddy has been grown in small pockets surrounding minor irrigation tanks. These tanks are basically impoundments of surface runoff by earthen embankments during the receding monsoons. The tanks have also been a source of additional revenue to the village communes called "communidades" during the late summer drawdown through the sale of fish naturally grown in them. Carambolim Lake is one such large semipermanent minor irrigation tanks known for its rich avifauna (Wagh, 1989; Sardesai et al., 1995).

The Konkan Railway project was initiated in 1990, to link the long isolated west coast region between Mumbai and Mangalore with the rest of the railway network in the country. But the project got muddled with environmental controversies, especially in the Goa region. One of the major concerns of environmentalists and bird lovers was the likely damage to the birdlife at Carambolim Lake by the project, since as per the pilot plan the tracks were to bisect the lake. But in the absence of detailed scientific data on the flora and fauna of the lake, the defence to their stand was an uphill task. However, their onerous struggle resulted in a marginal concession in the form of shifting of the track alignment towards the edge of the lake.

Though the importance of studying the avifauna of the lake was stressed by one of the authors (Heblekar \& Shanbhag,1992) in as early as 1992 , due to some technical snags, there was an inordinate delay until 1996 in initiating the work. By then, the construction work towards laying of tracks in the lake's immediate vicinity was in full steam. However, going by the 
dictum "better late than never", detailed census work on the bird fauna of the lake was initiated in January 1996 and carried out at regular monthly intervals until June 1998.

The construction activities for track laying were at their peak at the beginning of the year 1996, which went on tapering by the year end. Following this, the trial runs of engine and goods trains got initiated at the beginning of the year 1997. Regular train services commenced by the mid of the year. Therefore, the present communication compares the qualitative and quantitative picture of the avifauna at Carambolim Lake during two crucial years, 1996 and 1997, in an attempt to throw some light on the impact of the railway project, if any, on the avifauna during its construction and operational/implementation phases.

\section{Study area}

Carambolim Lake $\left(73^{\circ} 55^{\prime} \mathrm{N}\right.$ and $\left.15^{\circ} 30^{\prime} \mathrm{E}\right)$ is at a distance of $12 \mathrm{~km}$ from Panjim, the capital city of Goa. It spreads over an area of $70 \mathrm{ha}$, of which $40 \mathrm{ha}$ is chiefly water-laden central area surrounded by grassland. The western embankment of the lake serves as the base for the recently laid railway track. The eastern side has been partially cleared of its scrub forests and mango and cashew groves to pave way for the construction of residential tenements. The lake boundaries on three sides are fringed by coconut and mango trees. The sluice gate at the southeastern side of the lake is kept closed from late July to early May. The impounded water is used for irrigating the rabi crop of paddy in the lower reaches on the southern side of the lake. Except for the central zigzag watercourse, the lake bed is flat with the greatest depth of $2.75 \mathrm{~m}$ being at the sluice gate point. The lake holds up to $20,34,211.12 \mathrm{~m}^{3}$ of water during post monsoon owing to the impoundment of surface runoff by the closure of the sluice gate. Nymphea stellata, a rooted plant with floating leaves, Oryza rufipogon, emergent wild paddy and Hydrilla verticillata, a submergent, are the predominant aquatic plants in the lake.

\section{Climate}

The climate of Goa is greatly influenced by the South West monsoons. The state receives a total of $320 \mathrm{~cm}$ of rainfall annually, the bulk of which occurs during the monsoon months from June to September, with the wind speed reaching up to $15 \mathrm{~km} / \mathrm{hr}$. The summer months spanning from March to May are the hottest months of the year with the temperatures rising to almost $34^{\circ} \mathrm{C}$. The temperatures in winter may drop to $18^{\circ} \mathrm{C}$.

\section{Materials and Methods}

An initial checklist of birds at the lake was raised by sighting the birds with $8 \times 50$ binoculars and 15-45x60 field scope during a few random trips to the lake. Appropriate field guides (Ali, 1979; Woodcock, 1980; Sonobe \& Usui, 1992) and the compact handbook by Ali and Ripley (1983) were used for the purpose. Based on the regularly updated checklist the detailed census of birds was conducted by total count method, by dividing the lake into arbitrary sectors. Block method (Howes \& Blackwell, 1989) was employed for the enumeration of densely packed flocks. The study was conducted at monthly intervals from January 1996 to July 1998 by scanning the lake from four vantage points on the contour. The morning hours, 0800 to 1000 , were utilised for the purpose. The monthly totals of individual species were utilised to arrive at the cumulative annual/biannual total of respective species and the total bird population. The biannual cumulative total of individual species was used to decide the rank of dominance in relation to all other species encountered in the area.

\section{Observations}

The checklist of birds sighted at the lake environs during the two-year study, the residential status and abundance is provided in Table 1. Of the 92 species of birds sighted at the lake, a large number totalling 54 species of terrestrial birds constituted only 1.5 per cent of the population, whereas 98.5 per cent of the population was constituted by a relatively small number of aquatic birds consisting of 38 species. In terms of species strength of families represented, Passeridae was the largest with 11 species followed by Ardediae ( 7 species), Corvidae (6 species) and Anatidae (5 species).

The Cattle Egret, Bubulcus ibis was the most dominant resident which occupied the third rank of dominance on the whole. Though the lake supported a large number of resident species, it also patronised 21 species of migrant birds, which included three long distance migrants - Northern Pintails (Anas acuta), Garganey (A. querquedula) and Northern Shoveller (A. clyptea). Pintails were the most prominent species, monthly populations of which reached up to 6000, followed by Lesser WhistlingDucks, Dendrocyna javanica, reaching little over 3000 in strength and the Common Coots, Fulica atra surpassing the 500 mark. None of the dominant species were found to use the lake as a night roost. They thronged the lake in flocks in the morning, were found busily foraging during the whole day, but for a reduced feeding intensity during noon hours and left the lake at dusk to sites hitherto not known.

\section{Comparison of the bird population during 1996 and 1997}

Twenty-three additional species of birds (Table 1) were sighted in the lake area during 1997 over those sighted in 1996. Most of them were in small numbers on a cumulative basis, occupying lower ranks of dominance from 40-43. However, three species namely, Brown-headed Gull (Larus brunnicephalus), Rosy Starling (Sternus roseus) and Wood Sandpiper (Tringa glareola), were found in relatively large numbers, thereby occupying dominance ranks between 26 and 32 .

The mean monthly population of birds in the lake during the period of study with respect to seasons is provided in Table 2 . There was a perceptible rise in the mean monthly population of 
Table 1. A systematic list of birds with their status and abundance in Carambolim Lake during the two years of study (January 1996 - June 1998).

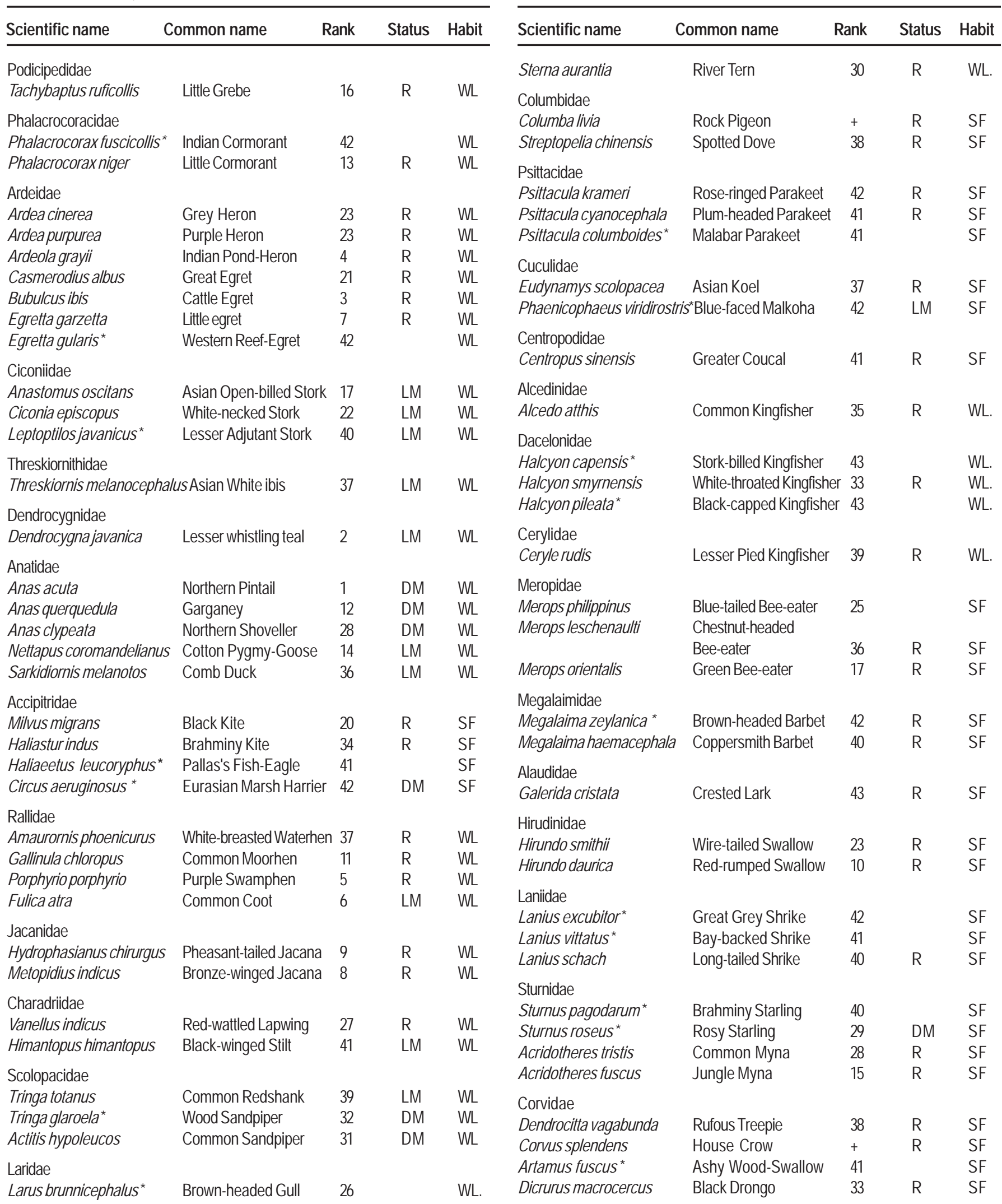




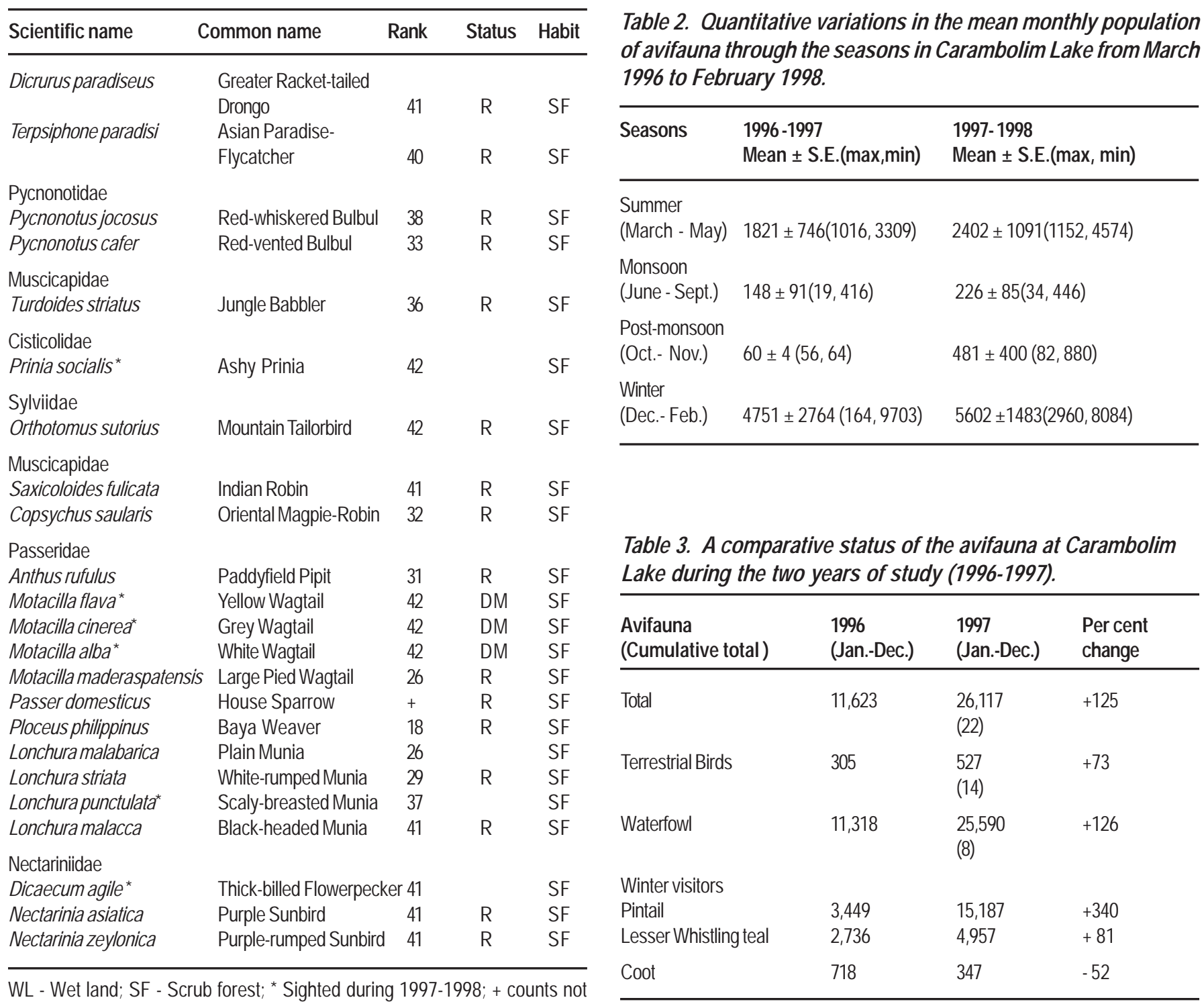

maintained; R - Resident; LM - Local migrant; DM - Distant migrant.

Common names are according to Manakadan et al. (1998).
Note: the numbers in parenthesis indicates the number of additional species of birds newly sighted during the year. 
birds in all the seasons during 1997-98 as compared to that during the year 1996-97.

The gross comparison of major components of the avifaunal population during the years 1996 and 1997 is provided in Table 3. There was a definite rise in the cumulative population of birds including that of waterbirds during the year 1997 when compared to that of 1996 nearing 125 per cent. The annual cumulative number of Pintails rose by over three fold during the year 1997. Likewise, the overall population of Lesser WhistlingDucks, the next dominant species, increased from 2736 to 4957. But interestingly the population of coots during 1997 reduced to half of that recorded during the previous year.

\section{Discussion}

Saha and Dasgupta (1992), compiled the information available to that date on the birds of Goa and listed 208 species. Lainer (1999a,b) recorded 382 species based on 1300 field trips spread over a period of 13 years since 1980. In this background, Carambolim Lake with its immediate surroundings harbouring 92 species of birds (24.08\% of the diversity of the state) is an important area deserving all round efforts towards its conservation. Besides, its importance is all the more heightened as it patronises over 17 species of winter visitors in the form of long distant migrants especially Pintails as well as local migrants such as the Lesser Whistling-Ducks, which throng the lake in thousands, year after year. Considering all these facts, the deep concern expressed by bird lovers on the likely impact of the alignment of the railway tracks in the immediate neighbourhood of the lake and the tough resistance rendered by them seems to be amply justified.

From a qualitative angle, 22 more species of birds were sighted during the year 1997. But many of these were terrestrial birds like shrikes, parakeets and malkohas, which might have got displaced towards the lake environs owing to the clearance of the neighbouring scrub forests to pave way for the ever increasing residential layouts. Secondly, birds like Brown-headed Gulls and Rosy Starlings, which generally move in large flocks may probably have strayed into the area from the neighbouring estuaries and scrub jungles respectively. At this juncture it may have to be noted that birds like Western Reef Egrets and Brownheaded Gulls are not the normal inhabitants of freshwater lakes. Some other species occupying tail end dominance ranks, sighted during the year, could be the ones which might have escaped enumeration/census during the previous year by mere chance factor, due to their extremely small numbers and also the widely spaced census interval of a month. Therefore, reasonable restraint is needed before drawing the conclusion that the sighting of a good number of additional species during the year 1997 , is in anyway an indicator of qualitative improvement of bird fauna.
Under these circumstances, our analysis of the impact of the railway project on the avifauna of the lake, if any, hinges around quantitative data. The earliest available quantitative data on birds/waterfowl of Carambolim Lake, prior to the present study is by way of Asian Midwinter Waterfowl Census, AWC (Perennou et al., 1994; Lopez \& Mundkur, 1997). But, unlike AWC, the plan of the present study is hinged on year round census carried out strictly on a monthly basis. Further, the reference data on Carambolim Lake available through AWC is of a highly fragmentary nature based on merely four counts across the compilation span of 10 years from 1987 to 1996. According to the five-year mean for a period from 1987-1991 (FYM, based on 3 counts of AWC), Carambolim Lake alone hosted 25 per cent $(30,000)$ of the total 1,20,972 Pintail Ducks that arrived in India. The only other AWC count carried out at the lake was in 1994. Surprisingly however, during that year, although a mammoth increase was observed in the number of Pintail Ducks that migrated to India (from 1,20,972 in 1987-1991 to 3, 89,290 in 1994), only 6,000 of them were found at the Carambolim Lake. Further, even though the decline in national figures for pintails in 1996 was only marginal as compared to those of 1994, the present study registered a noticeable decline in their strength at Carambolim Lake. Such a decline for all possibilities could be due to an extreme level of disturbance/ distraction caused by the movement of trucks, earthmovers, tippers, labour force and the incessant clouds of dust at the site, coinciding with peak construction activity. During the course of the present study itself, a substantial increase in the population of Pintail Ducks was observed during the subsequent year, 1997. Though published national figures for comparison are not available for the year under consideration, it can safely be construed as the recovery from the previous year's disturbance at the site. The latest AWC data available for Carambolim Lake for the year 1994, the detailed observations for the two years of current study 1996, 1997, and the continued monitoring of the winter population of the birds in the lake by the authors till date, collectively put the strength of winter visiting Pintail Duck population in the range of 5000-7000. Therefore, the FYM of 30,000 Pintails during 1987-1991, amounting one fourth of the national figures recorded for the species, registered for Carambolim Lake with a water spread of barely 40ha need to be taken with utmost caution and restraint.

The lake also harbours about four per cent of the Lesser Whistling Teal population of the country annually. However, the decline in their population from 1204 in 1994 to 912 in 1996, even though there was a considerable increase in the national figures (from 95,763 in 1994 to 1,15,660 in 1996, AWC records), may also be attributed to the disturbances caused to the lake environs owing to the track laying and construction activities of the Konkan Railways. The 84 per cent increase in their numbers in 1997 over those of 1996, indicates that their population visiting the lake must have picked up fast. This can 
be further substantiated by the continued ongoing winter monitoring by the authors. Thus, the impressive improvement in the population of winter visitors, waterfowl and the birds in general during 1997, a year wherein the din of construction activity came to a practical halt and the train services went into operation, appear to be encouraging signs. May be that the birds have learnt to live with the modern trends of the developing world! The precautions adopted by the Konkan Railway Corporation Ltd., in the form of tree plantations on the slopes of the embankments muffling the sounds of moving trains, declaration of the area as 'no hooting zone', etc. must have had their credit in improving the bird life in the lake.

In days to come, studies of such nature continued and conducted meticulously may have to stand testimony to the cautiously drawn conclusions as of now. All the same the lake is not free from other threats such as private encroachments, night soil generated by the floating population, and the incessant silt deposition leading to the development of marshy conditions. The authors are in touch with the top brass of local bodies, to explore the possibilities of setting the lake free from these threats so as to protect its integrity as a model citadel of aquatic birds in the region for the benefit of posterity.

\section{Acknowledgements}

We thank the authorities of the Goa University for facilitating the study. The U.G.C. unassigned grants through M.R.P. scheme to ABS supported the work.

\section{References}

Ali, S. (1979). The Book of Indian Birds. Bombay Natural History Society, Mumbai.

Ali, S. and S.D. Ripley (1983). Compact Handbook of Birds of India and Pakistan. Oxford Univ. Press, Mumbai.

Heblekar, Y.A. and A.B. Shanbhag (1992). Some observations on avifauna of Goa. Proceedings of the Seminar on Biodiversity of Goa, P.E.S College, Goa, India, pp 33-35.

Howes, J. and D. Blackwell (1989). Shorebirds Manual. AWB publication no. 55, Kuala Lumpur.

Lainer, H. (1999a). The birds of Goa (Part I). Journal of the Bombay Natural History Society 96(2): 203-220.

Lainer, H. (1999b). The birds of Goa (Part II). Journal of the Bombay Natural History Society 96(3): 405-422.

Lopez, A. and T. Mundkur (Eds.) (1997). The Asian Waterfowl Census 1994-1996. Results of the Coordinated Waterbird Census and an overview of the Status of Wetlands in Asia. Wetlands International, Kuala Lumpur.

Manakadan, R., J.C. Daniel, A.R. Rahmani, M. Inamdar and G. Ugra (1998). Standardized English common names of the birds of the Indian subcontinent - a proposal. Buceros 3(2): 55, BNHS, Mumbai. Perennou, C., T. Mundkur, D.A. Scott, A. Follestad and L. Kvenild (1994). The Asian Waterfowl Census 1987-91: Distribution and Status of Asian Waterfowl. AWB Publication No. 86. IWRB Publication No. 24, AWB, Kuala Lumpur, Malaysia and IWRB, Slimbridge, UK, 372 pp.

Saha, B.C. and J.M. Dasgupta (Eds.) (1992). Birds of Goa. Zoological survey of India, Calcutta.

Sardesai, B., V. Gowthaman and A. Gramopadhyaye (1995). Carambolim Lake. In: Directory of Indian Wetlands. W.W.F. (India) and Asian Wetland Bureau.

Sonobe, K. and S. Usui (Eds.) (1993). A Field Guide to the Waterbirds of Asia.Wild Bird Society of Japan, Tokyo.

Wagh, J. (1989). Carambolim (Mimeographed report). State Wildlife Board, Goa.

Woodcock, M. (1980). Collins Hand Guide to the Birds of the Indian Subcontinent. William Collins Sons and Co. Ltd. London. 